\title{
Papers
}

\section{Vacation ownership: Understanding the senior market}

Received (in revised form): 23 August 2005

\section{Tammie J. Kaufman}

has over 25 years of experience in the hotel, restaurant and travel industry. She has worked in all facets of the industry from management to line-employee positions. She has been teaching at Rosen College for four years.

\section{Randall Upchurch}

is professor of timeshare development at Rosen College. Dr Upchurch has over 21 years of experience in the lodging industry. In his present position Dr Upchurch is actively working with the American Resort Development Association to deliver a minor in timeshare development.

\section{Denver Severt}

has been an associate professor at Rosen College for three years. Prior to this, Denver taught for seven years at Eastern Michigan University. His research pivots around topics that relate to the customer's path to loyalty. Before joining academia, Denver worked in restaurant venues and country clubs for 25 years. He teaches graduate and undergraduate courses in accounting and guest service management for Rosen College.

\begin{abstract}
This study concerns consumer usage preferences relating to a leading timeshare developer's vacation club product. The discriminant analysis procedure was performed on the developer's year-end dataset to determine if there were any differences based upon the age of the timeshare owner concerning their product preferences. It was discovered that the older timeshare owner is more drawn to utilising products and services provided by their designated home resort while, in contrast, the younger timeshare owner is more likely to use timeshare exchange options and more inclined to purchase an additional timeshare interval at another company's resort.
\end{abstract}

\section{Keywords:}

timeshare, senior, marketing, segmentation

Randall Upchurch Rosen College of Hospitality Management University of Central Florida 9907 Universal Blvd Orlando, FL 32819, USA Tel: +14079038048 Fax: +14079038105 E-mail: rupchurc@mail.ucf.edu
Journal of Retail and Leisure Property (2006) 5, 95-103. doi:10.1057/palgrave.rlp.5100001

\section{INTRODUCTION}

As early as 1984 and as late as the early 1990s the introduction of major branded hotel chains into the timeshare marketplace paved the way for 
rapidly increasing consumer acceptance due to credibility gains based on the existing reputation of these early hotel company entrants. From the general public's perspective, the introduction of the hotel brands into the timeshare business brought about an elevated level of credibility and stimulated the development of differing product types and package offerings. ${ }^{1}$

The American Resort Development Association (ARDA) has estimated that approximately $12-15$ per cent of available timeshare product offerings are operated by branded hotel companies; however, this ratio is expected to change as these and other major brands continue to develop timeshare resorts. ${ }^{2}$ Furthermore, this wider acceptance of the timeshare product has driven annual sales up to nearly US\$9bn, with 6.2 million owners worldwide owning 9.9 million weeks. ${ }^{3}$ According to ARDA the timeshare industry has experienced an unheard of 1,000 per cent growth rate over the past two decades, and in 1999 was projected to show no signs of slowing down. ${ }^{4}$

Another factor that is responsible for the proliferation of the timeshare industry over the past decade is the availability of development capital through mainstream lending agencies. The backing by these reputable lending agencies has fuelled the win-win situation between developers with timeshare expertise and a public willing to spend money to ensure a quality vacation at a lower cost. This winning combination has led to an industry that is expanding in terms of revenue gains, number of owners and number of resorts in a worldwide fashion by leveraging sound financial principles. ${ }^{5}$

Yet another factor that has stimulated the perpetuation of the timeshare industry is based on the observation that consumers have more money than they have time to use for leisure purposes. Lazar and Hobson have found that time is an essential factor that has led to the growth in the industry. The time commitment associated with owning more than one home has caused people with the financial ability to choose the route of multiple week timeshare ownership. ${ }^{6}$

This unparalleled growth is of course not without its shortcomings. From the developer's perspective the Achilles' heel of the timeshare industry is the amount of money that is devoted to the marketing process. Hovey states that timeshares would be more palatable to the consumer if timeshare developers would reduce their initial pricing point via a reduction in marketing and sales expenses. In doing so, the industry would attract an even larger market that would naturally increase product acceptance on a global scale. ${ }^{7}$ Even with this issue at hand, consumers are now more amenable to the idea of purchasing a timeshare than in previous decades. ${ }^{8}$ But even if such a price reduction could be accomplished there is an existing need to understand the factors that attract consumers to consider and purchase timeshare products.

Elliot-White and Finn assert that leisure and vacation products have transitioned to a more customised, flexible, segmented product. ${ }^{9}$ The transition is evidenced in the move towards relationship marketing, where instead of pushing the product into the marketplace the primary effort is placed upon developing a lasting and trusting relationship. ${ }^{10}$ The move towards relationship marketing was made possible by narrowing the playing field through product segmentation as practised by the lodging 
industry. This practice of segmenting the market by product differentiation is practised by small- to medium-sized chains up to and including Fortune 500 companies like Cendant, InterContinental, Marriott and Hilton. ${ }^{11}$ Naturally this practice of product differentiation by the hotel brands is becoming a common practice in the timeshare industry as well.

Still, the timeshare industry as a whole has much to gain from lessons learned in the hotel industry. At the time of writing the major timeshare brands are enlisting their internal databases to access potential markets, while the independent timeshare developers have been somewhat reluctant to relinquish their reliance on existing point-intercept strategies. But both the branded and the independent timeshare developers are retooling their marketing strategies by incorporating a thorough review of consumer needs and wants relative to product and service offerings. In doing so, timeshare developers are seeking out consumer behaviour models that can make their sales and marketing programmes more efficient while increasing the attractiveness of existing and proposed timeshare products and services.

There are various strategies that may be imported from the lodging segment's extensive use of market segmentation. An example of current hotel practice that may be used to further refine the timeshare developers marketing programmes is the art of data mining. Data-mining technology is used to understand and then predict guest behaviour by information gained via asking consumers specific product and service questions. The basic goal of measuring existing consumption patterns as well as future consumption intentions is to enhance the developer's ability to segment future product and service offerings, which in turn enhances consumer satisfaction. ${ }^{12}$ Having responsive communication by determining the wants and needs of a desired market may result in a more satisfied market and give the companies a better ability to communicate their product more effectively to the sought-after market. ${ }^{13}$ The segments created through internal computer analysis help take away the human bias. ${ }^{14}$

In summary, utilising previous research and data mining can create a valuable template to elicit a better tool in which both the customer's needs are met and marketing costs are diminished by a more directed marketing approach. This approach will be valuable in predicting behaviour in the timeshare market. The first move in data mining the timeshare market is to look at the most viable market segment.

\section{THE TIMESHARE INDUSTRY'S VACATION CLUB CONCEPT}

The timeshare industry has been in the USA since the late 1960s, but the evolution of this segment of the hospitality industry has resulted in the timeshare product being packaged in such a way as to appeal to a variety of consumer leisure needs. During the 1970s and 1980s the timeshare product was sold predominately as a fixed week, or a float-week fashion whereby the purchaser was limited to a certain degree to the exact week or time interval of their vacation. Since the early 1990s the introduction of the vacation club concept became a mainstay in many developers' point-of-sale timeshare offering. The introduction of the vacation club concept came about as a direct reaction to the perceived inflexibility of 
the standard one-week timeshare offering whereby the consumer purchased a 'fixed' week (eg week 32) or a float week where the purchaser's interval varied within a set number of weeks each year. ${ }^{15}$ In simple terms a timeshare vacation club affords the timeshare owner the maximum flexibility via a point allocation system that equates to a certain size of unit, time of year and length of stay or some other combination of leisure or vacation services such as tourist attractions, tourist excursions, restaurant allowances or other travel services (eg cruises).

\section{THE MATURING SENIOR TRAVELLER}

With the ageing of the baby boom generation, an analysis of the senior travel market has become vital for success in a variety of tourism markets. NFO Plog Research notes that the maturing traveller classification is on the increase due to the ageing of the baby-boomer generation (1946 to 1964). They also note that these maturing travellers, between the ages of 45 and 64, have increased opportunities to travel and spend their discretionary dollars. ${ }^{16}$ In 2000 there were 61.2 million baby-boomers in or close to this prime travel age, and by 2010 this number is expected to increase by 30 per cent, to 79.6 million, and the 55 to 74 age category will see an increase in the total number of travellers. NFO Plog Research also reported that individuals in the over-55 age group were away from home on leisure travel an average of 19 nights in 2000, which was more than 1.5 times as many nights as the under-35 age group. Furthermore, seniors (for the purpose of this paper defined as over 55) spent approximately 1.5 times more on leisure travel than the under-35 age group. Moreover, the 65-plus age group was noted to have different priorities than younger travellers; 27 per cent of the 65-plus group cited 'lots of things to do' as a contributing factor when choosing a destination, as opposed to 37 per cent of all leisure travellers. Another interesting finding is that $24 \mathrm{r}$ per cent of travellers in the 55 to 64 age group and the 65 plus age group reported that destinations which offered historical and educational significance were important factors in making travel decisions.

In closing, it can be safely asserted that the ageing of the baby-boomer market (those born between 1946 and 1964) produces and will continue to produce noticeable gains in the in the volume of maturing travellers that seek out leisure and vacation destinations. ${ }^{17}$ Due to this growing body of maturing travellers, practitioners and academic researchers are attempting to benchmark changes in demand within this maturing senior market as the baby boomers grey. ${ }^{18}$

\section{STATEMENT OF PURPOSE}

The average timeshare owner tends to be older, making purchases after they are retired or their careers have been fully established. More than half of timeshare owners (58.6 per cent) are between the ages of 45 and 64 . Nearly a quarter ( 22.8 per cent) of timeshare purchasers are made by consumers who are 60 and over. ${ }^{19}$ The access to an increasing amount of disposable income coupled with the need to understand the wants and 
needs of this market better are evident. All of this lends support for monitoring senior market needs relative to the timeshare products, which to date has not been reported in the academic literature.

Clearly, the senior traveller does have the means to purchase a timeshare interval and has more discretionary time, which allows this type of traveller the luxury of vacationing at a timeshare resort. With those premises in mind, the purpose of this study is to determine the behavioural intentions of the senior timeshare segment when it comes to usage of their vacation club privileges and their expressed future consumption patterns.

Often individuals are referred to as seniors when they are 55 years or older. ${ }^{20-23}$ But a nationally accepted standard in the USA has been set by the American Association of Retired People and delineates seniors as an individual aged 50 years or older. ${ }^{24}$ For the purposes of this study a senior will be defined as an individual 50 years of age or older.

In summary, research suggests that there are differences between younger and older travellers in the type of experiences they seek while traveling. Therefore by studying the behaviour of senior owners, timeshare resort developers will be better able to comprehend what these individuals desire from their vacation club ownership.

\section{METHODOLOGY}

The return sample includes 2,544 owners from one of the leading timeshare companies that offers itsr product as a vacation club within the USA. There were initially 8,000 respondents randomly selected from the developer's six distinct resort clusters located within the USA. Two hundred and twenty-one surveys were returned as undeliverable, which lowered the initial sample size to 7,879 . As a result, the net response rate for this study was 32.2 per cent $(2,544 / 7,879)$.

The respondents filled out a survey including questions relating to characteristics of their current use patterns of their timeshare use, their expected frequency of usage over the next five years and what their behavioural intentions were relative to their vacation club membership. These items were set to a categorical scale of Yes or No, while age was self-reported, thus providing age groupings of younger versus senior timeshare owners. Due to the fact that a comparison was made between two groups (Yes/No as differentiated by age), each discriminant analysis consisted of one function. ${ }^{25}$ The means and significance were reported for analysis and demographics were represented by percentages and means.

\section{RESEARCH QUESTIONS}

The research questions for this study include the following.

- Is there a statistically significant relationship between a timeshare owner's age and their current timeshare consumption patterns?

- Is there a statistically significant relationship between a timeshare owner's age and their future consumption patterns? 


\section{RESULTS/DISCUSSION}

The mean age for the sample was 53. 6 years making the sample average to be termed as seniors according to the American Association of Retired People. This is important to note because Ragatz found in a recent national study that the average timeshare owner in the USA was 51 years old and the average household income was $\$ 121,639 .{ }^{26}$ Both findings reiterate the maturing nature of the leisure traveller, and that these timeshare travellers have access to discretionary income.

The difference between an older segment and a younger segment is supported by five different significant relationships, as noted in Table 1 . These findinggs indicate that owners who are older are more likely to use their home resort (ie where the member initially purchased their membership), both during their specified time and during alternate times. Table 1 also shows that the older owner is more likely to be attracted to their assigned home resort instead of exchanging into another resort via the vacation club's exchange option. It should also be noted that as age decreases these younger timeshare owners prefer to exercise their exchange option by vacationing at another timeshare resort either within the vacation club network or through an external exchange company's resort network. It was also discovered that the senior timeshare owner enjoys the flexibility of the vacation club's points system in that they are attracted by the option of converting their timeshare points for hotel stays as well as vacations on cruise ships.

Table 2 shows six different significant relationships present when looking at the timeshare owners' future travel plans as projected over the next five years. There is no significant difference between the senior timeshare owner and their younger counterparts when planning to use their specified time at their designated resort. Therefore, age is not a factor concerning this planned vacationing behaviour.

Relative to the current usage profile, the older timeshare owner shows a higher preference for using their designated resort at an optional (eg alternative) time during the year, while younger timeshare owners have a heightened preference to use their time at the other resorts within the timeshare developer's network of resorts. Again, the younger timeshare owner is still more interested in utilising the exchange resort option than the older timeshare owner.

An unusual unique finding regarding future product usage is that the younger timeshare owner is more likely to utilise their club points for

Table I: Current travel behaviour

\begin{tabular}{llll}
\hline & \multicolumn{2}{l}{ Average respondent age } & \\
\cline { 2 - 4 } & Yes & No & p-value \\
\hline Used specified time at Home resort & 57.12 & 52.15 & 0.000 \\
Used alternate time at Home resort & 56.06 & 52.75 & 0.000 \\
Vacationed at another member resort & 51.71 & 54.61 & 0.000 \\
Used an exchange resort & 51.63 & 54.26 & 0.000 \\
Used club points for hotel stay & 54.21 & 52.79 & 0.024 \\
Used club points for a cruise & 54.69 & 52.97 & 0.174 \\
\hline
\end{tabular}


hotel room nights than indicated by their current usage behaviour. Furthermore, there is projected shift in the preference for converting club points for a cruise within the next five years. It appears that the younger timeshare owner will show an increased interest in cruising as opposed to their current preference. Last, and unsurprisingly, there is significant difference at the 0.038 level, indicating that the younger timeshare owner plans on utilizing their points for adventure travel in the future.

Table 3 reflects three significant findings concerning vacation club members' desire to purchase additional points, purchase additional time at another vacation ownership resort, keep his or her existing level of points or liquidate their club membership by selling their points to someone else.

There is no significant difference between the two groups concerning the option of purchasing additional points based on their age. There is, however, a significant difference based on desire to purchase additional time at another vacation ownership resort, with the younger owners showing the highest preference. Relative to keeping club points at the present level, it was determined that the older timeshare owner leaned towards keeping the status quo versus their younger counterparts. Last, the more senior owners indicated that they had a propensity to sell their points. Based on age, it would appear that the older a timeshare owner gets the lower the perceived utility of retaining their club membership.

\section{TIMESHARE INDUSTRY IMPLICATIONS}

The results clearly show where there are differences in the current use versus planned usage of the timeshare vacation club product as

Table 2: Plans for the next five years

\begin{tabular}{llll}
\hline & \multicolumn{2}{l}{ Average respondent age } & \\
\cline { 2 - 4 } & Yes & No & p-value \\
\hline Use specified time at home resort & 53.21 & 54.10 & 0.141 \\
Use alternate time at home resort & 54.12 & 51.98 & 0.000 \\
Vacation at another member resort & 52.74 & 58.15 & 0.000 \\
Use an exchange resort & 52.78 & 55.29 & 0.000 \\
Use club points for hotel stay & 51.91 & 55.39 & 0.000 \\
Use club points for a cruise & 49.88 & 55.31 & 0.000 \\
Use club points for adventure travel & 52.13 & 53.54 & 0.038 \\
\hline
\end{tabular}

Table 3: Future plans for vacation club membership

\begin{tabular}{llll}
\hline & \multicolumn{2}{l}{ Average respondent age } & \\
\cline { 2 - 4 } & Yes & No & P-value \\
\hline Purchase additional points & 52.37 & 53.71 & 0.065 \\
$\begin{array}{l}\text { Purchase additional time at another vacation } \\
\quad \text { ownership resort }\end{array}$ & 48.58 & 54.95 & 0.000 \\
Keep points and do not buy any more & 55.04 & 49.73 & 0.000 \\
Sell points & 55.08 & 53.09 & 0.009 \\
\hline
\end{tabular}


differentiated by age of the owner. Basically, the timeshare owner who prefers spending time at their designated home resort tends to be older, versus the younger member who prefers the exchange option and spending time at another of the developer's participating club resorts. Overall, this relationship shows that the older timeshare owner would be drawn more to a single site offering versus the option of utilising many different locations. Therefore the focus of a developer's marketing campaign for the older consumer should be geared to the positive aspects associated with the resort amenities, attractiveness of the historical and educational surroundings and the safety and security of the home resort. This finding is also good news for the smaller resort company, in that they can market to the older segment due to their single-site preference.

At present the older timeshare owner has a preference for utilising their points for hotel stays and cruises excursions; however, this age preference will shift slightly in the future, with the younger owner being more likely to use points for this purpose. This should be viewed not necessarily as being a shift in preference but more a reflection of the ageing process. Regardless, the timeshare developer should be aware of this consumption pattern because it is directly related to the age of their ownership base and therefore indicates that developing materials or additional cruise line packages is certainly on the horizon.

The profile generated by the behavioural intentions listed in Table 3 is important to the developer because all four options have a direct impact on product and service consumptions levels. For instance, the younger owner is more likely than the older owner to seek out vacation experiences at other resort companies, which in turn presents a challenge for the developer's resort network in terms of scheduling, retail sales and use of on-site recreational and leisure services. A more important consideration is how the developer will maintain their owners' vacation club satisfaction and loyalty when their timeshare owners seek out these external leisure and vacation experiences.

Looking at the owners' response profile concerning keeping their existing points or in selling their membership, it would appear that developers are going to be challenged in how to keep their more senior timeshare owners satisfied. Granted that there is a time at which the ageing owner is no longer capable of extensive travelling, once this time occurs an appropriate exit strategy should be considered for the ageing consumer. This seems logical seeing that the ageing timeshare owner is loyal to a given resort and therefore has tremendous word of mouth potential for their vacation club product.

\section{SUGGESTIONS FOR FUTURE RESEARCH}

This research shows the need for more segmentation of timeshare owners relative to their wants and needs. Future research options are in abundance based on the limited empirical research in the timeshare industry. Specifically, the senior market needs to be explored and marketing plans developed as consumption preferences alter based on differences in age. This study suggests that further research should review the proclivity of the older timeshare owner to stay at a single resort site 
versus the option of exchanging their existing time for vacation experiences at other timeshare resorts. In doing so, strategies can be developed to overcome the rather obvious objections that the older timeshare owner has towards these and perhaps other vacation club alternatives.

Another body of research should focus on the shifting consumption patterns expressed by the younger timeshare owners concerning the attractiveness of the exchange option and in their preference for more than one resort location.

\section{References}

1. Upchurch, R. and Gruber, K. (2002), 'The evolution of a sleeping giant: Resort timesharing', International Journal of Hospitality Management, Vol. 21, No. 3, pp. 211-225.

2. Crotts, John and Ragatz, Richard (2002), 'Recent US timeshare purchasers: Who are they, what are they buying, and how can they be reached?' International Journal of Hospitality Management, Vol. 21, No. 3, pp. 227-238.

3. Scoviak, Mary (2003), 'A little bit of sunshine: Consumers' unwillingness to give up their holidays and a greater need for family time continue to support cautious optimism for timeshare and fractional ownership', Hotels, Vol. 37, No. 2, pp. 28-34.

4. American Resort Development Association (1999) State of the U.S. Vacation Ownership Industry: The 1999 Report, ARDA, Washington, DC.

5. Upchurch, R. (2002) ARDA Education Institute Resource Manual, ARDA, Washington, DC.

6. Lazar, J. and Hobson, W. (2002), 'Private residence clubs: A new concept for second home ownership', Journal of Leisure Property, Vol. 2, No. 2, pp. 105-120.

7. Hovey, M. (2002), 'Is timeshare ownership an investment product?' Journal of Financial Services Marketing, Vol. 7, No. 2, pp. 141-160.

8. Ragatz and Associates (2003) Resort Timesharing in the United States, Ragatz and Associates, Eugene, OR.

9. Elliot-White, M. and Finn, M. (1998), 'Growing sophistication: The application of geographical information systems in post-modern tourism marketing', Journal of Travel and Tourism Marketing, Vol. 7, No. 1, pp. 65-84.

10. Batterley, B. (2002), 'From CRM to RM', Marketing, October.

11. Watkins, E. (2003), 'Where's Bob now that we need him?' Lodging Hospitality, Vol. 11, No. 4, p. 4.

12. Magnini, V., Honeycutt, E. and Hodge, S. (2003), 'Data mining for hotel firms: Use and limitations', Cornell Hotel and Restaurant Administration Quarterly, Vol. 44, No. 2, pp. 94-105.

13. Bowen, J. (1997), 'A market-driven approach to business development and service improvement in the hospitality industry', International Journal of Contemporary Hospitality Management, Vol. 9, No. 7, p. 334.

14. Bowen, J. (1998), 'Market segmentation in hospitality research: No longer a sequential process', International Journal of Contemporary Hospitality Management, Vol. 10, No. 7, p. 289.

15. Upchurch and Gruber Ref. 1 above.

16. NFO Plog Research (2001).

17. Cook, S. (2001), 'North America, in Lockwood, A. and Medlik, S. (eds) Tourism and Hospitality in the 21st Century, Butterworth-Heineman, Oxford, pp. 172-180.

18. Del Rosso, L. (2000), 'The tie that binds', Travel Weekly, 24 August.

19. Ragatz and Associates Ref. 8 above.

20. Kotler, P., Bowen, J. and Makens, J. (1996) Marketing for Hospitality and Tourism, Prentice Hall, Upper Saddle River, NJ.

21. Moschis, G., Lee, E. and Mathur, A. (1997), 'Targeting the mature market: Opportunities and challenges', Journal of Consumer Marketing, Vol. 14, No. 4, pp. 282-293.

22. Shoemaker, S. (1989), 'Segmentation of the senior pleasure travel market', Journal of Travel Research, Vol. 27, Winter, pp. 14-21.

23. Shoemaker, S. (2000), 'Segmenting the mature market 10 years later', Journal of Travel Research, Vol. 39, August, pp. 11-26.

24. American Association of Retired People, available at www.aarp.com.

25. Hair Jr, J.F., Anderson, R.E., Tatham, R.L. and Black, W.C. (1998) Multivariate Data Analysis, 5th edn, Prentice Hall, Upper Saddle River, NJ.

26. Ragatz and Associates, ref. 8 above. 